This is an author produced version of a paper published in Biodiversity and Conservation. This paper has been peer-reviewed and is proofcorrected, but does not include the journal pagination.

Citation for the published paper:

Hedin, J., Ranius, T., Nilsson, S. G., and Smith, H. G. (2008) Restricted dispersal in a flying beetle assessed by telemetry.

Biodiversity and Conservation.

Volume: 17 Number: 3, pp 675-684.

http://dx.doi.org/ 10.1007/s10531-007-9299-7

Access to the published version may require journal subscription.

Published with permission from: Springer

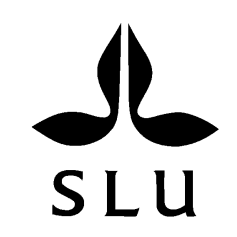

Epsilon Open Archive http://epsilon.slu.se 
Should be cited as: Hedin, J., Ranius, T., Nilsson, S.G. \& Smith, H.G. (2008) Restricted dispersal in a flying beetles assessed by telemetry. Biodivers Conserv 17:675-684

DOI 10.1007/s10531-007-9299-7

Available at: http://www.springerlink.com/content/100125/

\section{Restricted dispersal in a flying beetle assessed by telemetry}

Jonas Hedin $^{1,2}$, Thomas Ranius ${ }^{3 *}$, Sven G. Nilsson ${ }^{1}$ and Henrik G. Smith ${ }^{1}$

1Department of Ecology, Animal Ecology, Lund University, Ecology Building, SE-223 62 Lund, Sweden

${ }_{2}$ Current address: County administrative board of Kronoberg, SE-351 86 Växjö, Sweden

3Department of Ecology, P.O. Box 7044, Swedish University of Agricultural Sciences, SE-750 07

Uppsala, Sweden

* corresponding author

e-mail: thomas.ranius@ekol.slu.se

Tel. ++46186723 34, Fax ++4618672890 


\begin{abstract}
Many insects living in ancient trees are assumed to be threatened as a result of habitat loss and fragmentation. It is generally expected that species in habitats with low temporal variability in carrying capacity have lower degree of dispersal in comparison to those in more ephemeral habitats. As hollow trees are long-lived, species in that habitat are expected to be sensitive to habitat fragmentation, due to a low capacity to establish new populations far from present ones. Using radio telemetry, we studied the dispersal for a beetle, Osmoderma eremita, living in hollow trees. O. eremita exhibited philopatry and only dispersed over short ranges. $82-88 \%$ of the adults remained in the tree where they were caught. All observed dispersal movements ended up in nearby hollow trees and $62 \%$ in the neighbouring hollow tree. These results corroborate the suggestion that habitat fragmentation may be detrimental to insects living in temporally stable but spatially variable habitats. In order to preserve such species, we propose that conservation efforts should be focused on maintaining or increasing the number of suitable trees in and near presently occupied stands.
\end{abstract}

Key words: dispersal distance, dispersal rate, Osmoderma eremita, radio transmitters, sedentary, tree hollow 
Hedin et al.

\section{Introduction}

Many insect species living in coarse woody debris and ancient trees are assumed to be threatened as a result of habitat loss and fragmentation (Speight 1989; Berg et al. 1995). The colonisation ability affects which strategy that is the most efficient for preservation of this fauna. If the colonisation ability is low it is important that the conservation efforts are conducted close to sites where the target species are present (Huxel and Hastings 1999), while to protect species that colonise over long distances there should be more focus on sites where restoration efforts are inexpensive and may generate a quick increase in habitat quality (Ranius and Kindvall 2006). A low capacity to establish new populations far from present ones should especially be expected for species in habitats with low temporal and high spatial variability in carrying capacity, because they are assumed to have low dispersal rates (Southwood 1962; Johnson and Gaines 1990; Nilsson and Baranowski 1997; Travis and Dytham 1999). To study dispersal of woodliving insects is difficult, but recent genetic (Schmuki et al. 2006) and capture-recapture (Ranius and Hedin 2001) studies suggest limited dispersal for some species.

Osmoderma eremita is a $3 \mathrm{~cm}$ long flying scarabaeid beetle inhabiting hollow trees. Because a hollow tree persist for up to a few hundred years, local populations of this species can possibly live for $>50$ generations in the same tree. Tree hollows are an absolutely discrete habitat. The population structure of $O$. eremita, within stands of hollow trees (with distances of up to 250 m between individual trees), may be described as a metapopulation (Ranius 2000; Ranius and Hedin 2001). One hollow tree can potentially sustain a local population with up to one hundred adults per year (Ranius 2001). There are asynchronous fluctuations in population size between trees, but the total metapopulation size is remarkably constant (Ranius 2001). Using markrecapture, it has been estimated that $85 \%$ of adult beetles remained in the natal tree throughout 
Hedin et al.

their entire life (Ranius and Hedin 2001). The aim of this study was to obtain estimates of the dispersal patterns and dispersal rate of $O$. eremita using radio telemetry. This method has only recently been used in studies of flying woodliving insects (Hedin \& Ranius 2002; Rink \& Sinsch 2007). By this method we could obtain estimates of dispersal distance independent from the mark-recapture data. We thoroughly searched an area around each tree (radius $800 \mathrm{~m}$ ) much larger than the previously largest observed dispersal distance $(190 \mathrm{~m})$. In contrast to the markrecapture study, we could show where the dispersing individuals ended up (within the study area) regardless of endpoint. The results could be directly compared to those of the mark-recapture study performed in the same area.

\section{Methods}

\section{Study species}

The scarabaeid beetle $O$. eremita lives in hollow trees in the temperate and Mediterranean regions of Europe (Ranius et al. 2005). The larvae develop exclusively in the interior of hollow trees where they feed on rotten wood. Occupied trees contain large amounts of wood mould (loose rotten wood from the interior of the tree trunk often mixed with fungi, remains of animal nests and fragments of insects) (Ranius and Nilsson 1997; Dajoz 2000). In Sweden, pedunculate oak Quercus robur is the most important tree species for O. eremita (Antonsson et al. 2003). After two or three years of development, the larvae construct a cocoon and the metamorphosis takes place the following spring (Ranius et al. 2005). The adults emerge in July to August and live for a few weeks (Table 1) and never hibernate (own observations; Ranius et al. 2005). They mainly remain in the tree hollows and in northwestern Europe they have never been observed visiting flowers or sap flows (Ranius et al. 2005). The species is a good indicator for species richness of 
Hedin et al.

beetles associated with tree hollows (Ranius 2002a) and has been given the highest priority according to the European Union's Habitats Directive (Anonymous 1992).

\section{Study area and habitat inventory}

This study was conducted in July-August 1998-2000 in Bjärka-Säby 58¹6'N, 15²46'E and an area $10 \mathrm{~km}$ to the southwest, at Brokind $58^{\circ} 12^{\prime} \mathrm{N}, 15^{\circ} 40^{\prime} \mathrm{E}$, in the province of Östergötland, southeastern Sweden. We made an inventory of all hollow trees in these areas. We divided the hollow trees into two categories, those with: 1) tree hollows with large entrance holes $(>10 \mathrm{~cm}$ in diameter), assumed to be older and with a larger amount of wood mould (many litres), and 2) tree hollows with smaller entrance holes, assumed to be younger and with a smaller amount of wood mould. Since the vast majority of the trees occupied by $O$. eremita belong to the first category, only these trees were used in the analysis. We found 243 such suitable hollow trees $(+420$ hollow trees with small entrance holes) in an area of $40 \mathrm{~km}^{2}(8 \times 5 \mathrm{~km})$ in Bjärka-Säby and $52(+30$ hollow trees with small entrance holes $)$ in an area of $12 \mathrm{~km}^{2}(3 \times 4 \mathrm{~km})$ in Brokind. Below these trees are referred to as hollow trees. Most of these trees were concentrated to several smaller core areas with a high density of hollow trees. In Bjärka-Säby: Kalvhagen 31 trees in 15 ha, Hjorthagen 34 trees in 8 ha, Bjärka äng 28 trees in 19 ha and in Brokind: Brokinds skolhage 45 trees in 33 ha. Thus the density of hollow trees in these core areas ranged from $1.4-4.3$ / ha. Quercus robur was the dominating tree species among the hollow trees (92\% in Bjärka-Säby and $85 \%$ in Brokind). Other tree species that may form hollows suitable for O. eremita (Antonsson et al. 2003) and occur as hollow trees in the study areas are in decreasing proportions (between $6 \%$ and $0.5 \%$ each): Fraxinus excelsior, Tilia cordata, Sorbus intermedia, Acer platanoides, Alnus glutinosa, Fagus sylvatica, Malus sylvestris and Ulmus glabra.

From 1995 to 2007 (for some trees 1998-2007) we observed five wind-fallen trees among 
Hedin et al.

60 studied hollow oaks, which implies a falling rate of about $0.8 \%$ / year. Although it is not possible to know if the hollow trees remain suitable habitats for $O$. eremita during the entire lifetime as hollow trees, the low degradation rate nevertheless indicates that hollow trees typically remain over many decades.

\section{Radio telemetry}

The telemetric method, thoroughly described in Hedin and Ranius (2002), was developed and tested in 1997. In 1998-2000, we fixed 65 Holohil $^{\text {TM }}$ LB-2 $0.48-0.52$ g radio transmitters on 26 females and 39 males, each with a unique frequency. The mean mass of all beetles caught was $1.7 \mathrm{~g}$ for both males and females (S.D.=0.5). Individuals larger than the average were tagged with transmitters; their mean mass was $2.2 \mathrm{~g}($ S.D.= 0.4) for females and $2.4 \mathrm{~g}($ S.D. $=0.3)$ for males. Thus, the transmitters were $20-25 \%$ of the individuals' body mass. We tagged beetles with transmitters when they were captured in pitfall traps for the first time. The traps were empty jars placed in the tree hollows with the openings level with the wood mould surface, which were checked either daily or every second day. The transmitters were fixed on the pronotum of the adult beetles with the 5-cm antenna sticking out backwards. Attachment of the transmitter was affected with a strong, fast-setting adhesive (Loctite, type 416 Tak pak with type 7452 Tak pak accelerator, Göteborg, Sweden). The nominal life-time of the batteries in the transmitters was 1620 days. When we recaptured transmitter-tagged beetles with pitfall traps, the transmitters always remained on the beetles, but in some cases the transmitters had ceased to work (Hedin and Ranius 2002). We searched for the beetles with transmitters once a day, starting where the beetles were located the day before. Usually we established contact with the transmitter very quickly if the beetle remained in the same tree as the day before. When we could not find a beetle in a tree we searched in an area with a radius of $800 \mathrm{~m}$. We thoroughly walked through all parts of this area 
and this search process took several hours to perform. We lost contact with $71 \%$ of the females and $20 \%$ of the males before the end of the nominal life-time of the transmitter's battery (Hedin and Ranius 2002).

\section{Calculations of dispersal rate}

The simplest measure of dispersal rate is to calculate the ratio between the total number of dispersing transmitter-tagged beetles and the total number of transmitter-tagged beetles. However, beetles may disperse before we put on the transmitter or after the transmitter ceased to function. Further, some beetles might die before the transmitter stopped signalling. Therefore, we calculated an adjusted dispersal rate. This estimate was based on the assumption that dispersal propensity is constant over the entire life-time of the beetles. We made this assumption because the observed dispersal events were not biased towards the beginning or the end of the period the individuals were studied, neither in this study nor in the capture-recapture study. Because the movements of the beetles were observed during a period of similar to the mean life-time of the beetles (Table 1), and beetles were tagged with transmitter when they were captured for the first time, the period of study was probably rather close to the life-time of the beetles.

We used encounter history data from our parallel mark-recapture with pitfall traps set in the tree hollows (Ranius and Hedin 2001) to compute survival rates. We pooled data from both our study areas, but treated males and females separately. We made the calculations both for each year separately, and with data from the three years combined. We estimated survival rates using the Cormack-Jolly-Seber model (White and Burnham 1999) with recaptures only, with the aid of the program MARK (www.cnr.colostate.edu/ gwhite/mark/mark.htm). The estimate of mean life-time was calculated from the cumulative survival rate obtained by the program (Table 1).

Dispersals per day was calculated by dividing the number of observed dispersals (which 
never was more than one per day) by the total number of days individuals were tagged with working transmitters, corrected for the survival of beetles. Dispersal rate per life-time, $\mathrm{D}_{\text {life }}$ was estimated as:

$D_{\text {life }}=1-\left(1-D_{\text {day }}\right)^{\mathrm{m}} \quad$ eq. 1

where $D_{\text {day }}=$ dispersals per day and $m=$ mean life-time of adults.

\section{Results}

\section{Dispersal pattern}

The longest detected dispersal was $180 \mathrm{~m}$ and $88 \%$ (7/8) of the between-patch movements were less than $50 \mathrm{~m}$ (Fig. 1a). Also at distances of $180-750 \mathrm{~m}$ there were many hollow trees which potentially could have been end-points of the movements (Fig. 1b). Of all dispersal movements, $62 \%(5 / 8)$ were to the nearest standing hollow tree and the other three dispersal movements were to the second, third and seventh nearest standing hollow tree, respectively. Only one individual (male) dispersed further from the tree (the next neighbouring hollow tree) where it was found after the first flight (flight distance: $20+160 \mathrm{~m}$ ). Thus, all dispersal movements observed by telemetry were to other hollow trees that we in our tree inventory previously had considered as suitable habitats for $O$. eremita (see methods: habitat inventory). The observed dispersal events range from 10-180 m. We could not detect any differences between male and female dispersal ranges $(p=0.393$, Mann-Whitney $\mathrm{U}$ test).

\section{Dispersal rate}

The dispersal rate (measured as the quota between the total number of dispersing individuals with transmitters and the total number of transmitter-tagged individuals) was $12 \%(3 / 26)$ for females 
and $13 \%$ (5/39) for males (see Table 1). The adjusted mean dispersal rate was $18 \%$ for males (Table 1). Because the number of recaptured females (Ranius and Hedin 2001) was too low to give a reliable mean life time estimate, we were not able to calculate an adjusted dispersal rate for females.

\section{Discussion}

\section{Dispersal pattern}

The fact that we did not find any transmitter-tagged beetles in the radius interval of $200-800 \mathrm{~m}$ from the tree where captured (Fig. 1) suggests that dispersal is biased towards short distances (shorter than $200 \mathrm{~m}$ ) to hollow trees in the close vicinity of the natal tree. Male $O$. eremita beetles emit a pheromone to attract female $O$. eremita and some males may also take advantage of this signal from other males (Larsson et al. 2003). Thus, during dispersal females but possibly also males can use the odour signal from males to find suitable hollow trees. It is not yet known at how long distances the odour signal can be received, but apparently it works very well at short distances (10-50 m) from suitable hollow trees (Larsson et al. 2003).

In our telemetric study we were not able to detect any sex differences in dispersal distances, but the number of observed dispersal events was quite low (Table 1). One possible explanation for the fact that we lost contact with $71 \%$ of the females and $20 \%$ of the males before the end of the nominal life-time of the batteries could be that many females frequently emigrate more than $800 \mathrm{~m}$ from the natal tree. That is however highly unlikely, because in a landscape $\left(10 \times 15 \mathrm{~km}^{2}\right)$ with a large number of occupied hollow trees, the frequency of presence of $O$. eremita was lower in trees in small stands (Ranius 2002b), which would not be the case if migrating beetles readily colonised such trees. A more probable explanation is that the 
Hedin et al.

transmitters ceased to work due to damage by water and broken antennas as was confirmed in some cases (Hedin and Ranius 2002). There is a difference in the behaviour between males and females which is reflected in higher capture rates in pitfall traps for males (see below), and it may also generate differences in the frequency of damaged transmitters.

\section{Dispersal rate}

The results for males and females are consistent with previous estimations of a dispersal rate of $15 \%$ (95\% conf. limits: 6-28 \%) from mark-recapture data (Ranius and Hedin 2001). Thus, only one out of seven $O$. eremita individuals leave their natal tree according to these two independent studies. Even though the sex ratio in the trees is even, the number of captured females is always much smaller than that of males (Ranius 2001). This can be due to behavioural differences where females are occupied with egg-laying deep in the wood mould most of their adult life-time and only occasionally visit the wood mould surface to copulate, whereas males are more active near the wood mould surface with the pitfall traps trying to copulate. As a result, we have a comparatively low number of recaptures of females resulting in an uncertain estimate of female dispersal rate. Therefore we cannot determine if there is a sex-difference in dispersal rate. The combination of a low dispersal rate and the fact that we did not detect any beetles dispersing more than $200 \mathrm{~m}$ up to the detection interval of $800 \mathrm{~m}$ make us suggest that long distance dispersal, in this case $>200 \mathrm{~m}$, is rare. In contrast, forest beetles dependent on ephemeral resources that only develop one generation in each habitat have dispersal ranges of several kilometres during their adult life-time (e.g. Nilssen 1984; Creighton and Schnell 1998; Cronin et al. 2000, Nilsson et al. 2001).

\section{Extinction risk}


Hedin et al.

In Sweden, the amount of old hollow oaks was very large near farms in the agricultural landscape in the beginning of the 19th century, thanks to a state ban since 1558 on cutting oaks on private and church properties. The end of this ban in 1830 led to a drastic decrease in the number of old hollow oaks during the 19th century (Eliasson and Nilsson 2002). Furthermore, the recruitment of new hollow trees has been severely disrupted due to intensive cutting of timber oaks during the last two centuries. Thus, in the fragmented old oak landscape of Sweden today, the number of suitable hollow trees in each stand with O. eremita is usually very small (often only about 10 suitable trees, Antonsson et al. 2003). O. eremita may be able to survive in such stands for long periods of time because of the low emigration rate (cf. Thomas 2000), long life-time of the old hollow trees and the asynchronous population fluctuations between hollow trees (Ranius 2001). However, in the absence of regeneration of new hollow trees within or nearby these stands, populations will sooner or later go extinct. At the same time colonisation in new suitable stands arising far away from existing populations is unlikely; this study indicates that the probability of colonisation decreases severely at a distance of just a few hundred metres. Due to the limited number of migrating individuals tracked, we cannot draw any conclusions about long-distance dispersals that might occur at rare occasions, but still may be important for the long-term persistence of the species at a landscape scale. In addition, we cannot exclude that dispersal distances would have been larger in the case of no or low habitat availability close to the original habitat. Therefore, we cannot conclude at which distances and at which sizes and configurations of dispersal sources the colonisation rate reach critically low values.

The increased fragmentation of habitat in the landscape may affect the evolution of dispersal distances (Macdonald and Johnson 2001). Empirical data concerning the evolution of dispersal rates and dispersal distances in a changing environment with a large habitat loss and increasing fragmentation is however scarce (Hanski 2001). If fragmentation has occurred to an 
extent where no successful dispersal outside stands occur, evolution of increasing dispersal distances in response to increased fragmentation may not be possible.

\section{Conclusions for nature conservation}

Since the majority of the present Swedish populations of $O$. eremita inhabit only a few trees and the distance to the nearest other population often seem too large (often >>10 km) to permit dispersal, many of the existing populations of the species in Sweden today can be seen as an extinction debt (Tilman et al. 1994) that will be paid for in the future if there will be no recruitment of hollow trees within the next 50-100 years. Therefore, we propose that conservation efforts should focus both on preserving remaining $O$. eremita populations in stands of hollow trees and creating new suitable hollow trees near these (most within $200 \mathrm{~m}$ distance), possibly by speeding up the creation of hollows in present young and medium-age trees (Key and Ball 1993; Ranius 2002b). Thus, in order to preserve O. eremita we need to establish where it occurs in the landscape instead of solely relying on geographical information on the distribution of suitable habitats (Huxel and Hastings 1999; Nilsson et al. 2001). Distributional patterns indicate that several other species dependent on tree hollows have limited colonisation capacity (Nilsson and Baranowski 1997), however, there are also data indicating that $O$. eremita may have a lower dispersal rate than most other beetle species inhabiting hollow oaks (Ranius 2006).

If the aim is to protect all species, the conservation efforts must be adopted to those species in the community that are most sensitive to habitat loss and fragmentation. In this respect, O. eremita may be one suitable umbrella species, although some other species are rarer and may need larger groups of hollow trees to persist. Such species are some predators on hollow-living insects, e.g. the click beetle Elater ferrugineus preying on O. eremita (Svensson et al. 2004). 
Acknowledgements - We thank our field assistants and Bengt Hansson, Andreas Malmqvist and Håkan Ljungberg for valuable comments. Kjell Antonsson provided some data on hollow trees and lent out GPS-equipment. Jon Loman, Ulf Wiktander and Ola Olsson lent out their receivers. This study was supported by the Mistra-project SUFOR to S.G. Nilsson, Stiftelsen Eklandskapet i Linköpings kommun, Larsénska fonden and the Royal Swedish Academy of Sciences. H. Smith and T. Ranius were supported by Formas.

\section{References}

Anonymous (1992) Directive 92/43 of the council of the European Community on the conservation of habitats and wild flora. European Community, Brussels

Antonsson K, Hedin J, Jansson N, Nilsson SG, Ranius T (2003) Läderbaggens (Osmoderma eremita) förekomst i Sverige [Occurrence of the hermit beetle (Osmoderma eremita) in Sweden. In Swedish, English abstract]. Entom Tidskr 124:225-240

Barrowclough GF (1978) Sampling bias in dispersal studies based on a finite area. Bird Banding $49: 333-341$

Berg Å, Ehnström B, Gustafsson L, Hallingbäck T, Jonsell M, Weslien J (1995) Threat levels and threats to red-listed species in Swedish forests. Cons Biol 9:1629-1633

Creighton JC, Schnell GD (1998) Short-term movement patterns of the endangered American burying beetle Nicrophorus americanus. Biol Cons 86:281-287

Cronin JT, Reeve JD, Wilkens R, Turchin P (2000) The pattern and range of movement of a checkered beetle predator relative to its bark beetle prey. Oikos 90:127-138 
Hedin et al.

Dajoz R (2000) Insects and forests - the role and diversity of insects in the forest environment. Intercept, Paris

Eliasson P, Nilsson SG (2002) 'You should hate young oaks and young noblemen' -the environmental history of oaks in $18^{\text {th }}$ and $19^{\text {th }}$ century Sweden. Environ Hist 7:659-677

Hanski I (2001) Population dynamic consequences of dispersal in local populations and in metapopulations. In: Clobert J, Danchin E, Dhondt AA, Nichols JD (eds) Dispersal. Oxford University Press, Oxford, pp 283-298

Hedin J, Ranius T (2002) Using radio telemetry to study dispersal of the beetle Osmoderma eremita, an inhabitant of tree hollows. Comput Electron Agric 35:171-180

Huxel GR, Hastings A (1999) Habitat loss, fragmentation and restoration. Restor Ecol 7:309-315

Johnson ML, Gaines MS (1990) Evolution of dispersal: theoretical models and empirical tests using birds and mammals. Annu Rev Ecol Syst 21:449-480

Key RS, Ball SG (1993) Positive management for saproxylic invertebrates. In: Kirby KJ, Drake CM (eds) Dead wood matters: The ecology and conservation of saproxylic invertebrates in Britain. English Nature Science No. 7. English Nature, Peterborough, pp 89-105

Koenig WD, van Vuren D, Hooge PN (1996) Detectability, philopatry, and the distribution of dispersal distances in vertebrates. Trends Ecol Evol 11:514-517

Larsson MC, Hedin J, Svensson GP, Tollasch T, Francke W (2003) The characteristic odour of Osmoderma eremita (Coleoptera: Scarabaeidae) identified as a male released pheromone. J Chem Ecol 29:575-587

Luce JM (1996) Osmoderma eremita (Scopoli, 1763). In: van Helsdingen PJ, Willemse L, Speight MCD (eds) Background information on invertebrates of the Habitats Directive and 
the Bern Convention. Part 1: Crustacea, Coleoptera and Lepidoptera. Council of Europe, Strasbourg, pp 64-69

Macdonald DW, Johnson DDP (2001) Dispersal in theory and practice: consequences for conservation biology. In: Clobert J, Danchin E, Dhondt AA, Nichols JD (eds) Dispersal. Oxford University Press, Oxford, pp 341-357

Nilssen AC (1984) Long-range aerial dispersal of bark beetles and bark weevils (Coleoptera, Scolytidae and Curculionidae) in northern Finland. Ann Entomol Fenn 50:37-42

Nilsson SG, Baranowski R (1997) Habitat predictability and the occurence of wood beetles in old-growth beech forests. Ecography 20:491-498

Nilsson SG, Hedin J, Niklasson, M (2001) Biodiversity and its assessment in boreal and nemoral forests. Scand J For Res Suppl 3:10-26

Ranius T (2000) Minimum viable metapopulation size of a beetle, Osmoderma eremita, living in tree hollows. Anim Conserv 3:37-43

Ranius T (2001) Constancy and asynchrony of Osmoderma eremita populations in tree hollows. Oecologia 126:208-215

Ranius T (2002a) Osmoderma eremita as an indicator of species richness of beetles in tree hollows. Biodiv Cons 11:931-941

Ranius T (2002b) Influence of stand size and quality of tree hollows on saproxylic beetles in Sweden. Biol Cons 103:85-91

Ranius T (2006) Measuring the dispersal of saproxylic insects: a key characteristic for their conservation. Popul Ecol 48:177-188 
Ranius T, Hedin J (2001) The dispersal rate of a beetle, Osmoderma eremita, living in tree hollows. Oecologia 126:363-370

Ranius T, Kindvall O (2006) Extinction risk of wood-living model species in forest landscapes as related to forest history and conservation strategy. Landscape Ecol 21:687-698

Ranius T, Nilsson SG (1997) Habitat of Osmoderma eremita Scop. (Coloptera: Scarabaeidae), a beetle living in hollow trees. J Insect Conserv 1:193-204

Ranius T, Aguado LO, Antonsson K, Audisio P, Ballerio A, Carpaneto GM, Chobot K, Gjurašin B, Hanssen O, Huijbregts H, Lakatos F, Martin O, Neculiseanu Z, Nikitsky NB, Paill W, Pirnat A, Rizun V, Ruicănescu A, Stegner J, Süda I, Szwałko P, Tamutis V, Telnov D, Tsinkevich V, Versteirt V, Vignon V, Vögeli M, Zach P (2005) Osmoderma eremita (Coleoptera, Scarabaeidae, Cetoniinae) in Europe. Animal Biodiv Conserv 28.1:1-44

Rink M, Sinsch U (2007) Radio-telemetric monitoring of dispersing stag beetles: implications for conservation. J Zool 272:235-243

Schmuki C, Vorburger C, Runciman D, MacEachern S, Sunnucks P (2006) When log-dwellers meet loggers: impacts of forest fragmentation on two endemic log-dwelling beetles in south-eastern Australia. Mol Ecol 15:1481-1492

Southwood TRE (1962) Migration of terrestrial arthropods in relation to habitat. Biol Rev $37: 171-214$

Speight MCD (1989) Saproxylic invertebrates and their conservation. Council of Europe, Publications and Documents Division, Strasbourg 
Svensson GP, Larsson MC, Hedin J (2004) Attraction of the larval predator Elater ferrugineus to the sex pheromone of its prey, Osmoderma eremita, and its implication for conservation biology. J Chem Ecol 30:353-363

Thomas CD (2000) Dispersal and extinction in fragmented landscapes. Proc R Soc Lond B 267:139-145

Tilman D, May R, Lehman CL, Nowak MA (1994) Habitat destruction and the extinction debt. Nature 371:65-66

Travis JMJ, Dytham C (1999) Habitat persistence, habitat availability and the evolution of dispersal. Proc R Soc Lond B 266:723-728

White GC, Burnham KP (1999) Program MARK: survival estimation from populations of marked animals. Bird Study 46:120-139 
Hedin et al.

\section{Tables.}

Table 1. Data on the dispersal of Osmoderma eremita from a telemetric study. Mean life-time was estimated based on data from a parallel capture-recapture study.

$\begin{array}{llllll} & \text { Sex } & 1998 & 1999 & 2000 & \text { Total } \\ \text { No. beetles with transmitters } & \mathrm{F} & 13 & 6 & 7 & 26 \\ & \mathrm{M} & 12 & 23 & 4 & 39 \\ \text { No. dispersing individuals } & \mathrm{F} & 1 & 2 & 0 & 3 \\ & \mathrm{M} & 2 & 1 & 2 & 5 \\ \text { Dispersal rate (\%) } & \mathrm{F} & 7.7 \% & 33 \% & 0 \% & 12 \% \\ & \mathrm{M} & 17 \% & 4.3 \% & 50 \% & 13 \% \\ \text { Mean life-time (days) } & \mathrm{F} & - & - & - & - \\ & \mathrm{M} & 18 & 13 & 14 & 16 \\ \text { Daily dispersal rate } & \mathrm{F} & - & - & - & - \\ & \mathrm{M} & 1.5 \% & 0.45 \% & 4.5 \% & 1.2 \% \\ \text { Adjusted dispersal rate } & \mathrm{F} & - & - & - & - \\ & \mathrm{M} & 24 \% & 6 \% & 48 \% & 18 \% \\ \text { Days with } & \mathrm{F} & 0.62 & 0.68 & 0.66 & 0.65 \\ \text { functional transmittors/ } & \mathrm{M} & 0.97 & 0.93 & 0.95 & 0.95 \\ \text { total transmittor days } & & & & & \end{array}$


Figure $1 \mathrm{a}$ ) The number of dispersing beetles per $50 \mathrm{~m}$ from the natal tree, in the telemetric study conducted in 1998-2000 (black) and mark-recapture study conducted in 1995-2000 (grey). b) The number of hollow trees per $50 \mathrm{~m}$ from the natal tree (mean for the 22 observed dispersals), in absolute numbers (divided by 100, black) and in numbers per hectare (grey).

a)

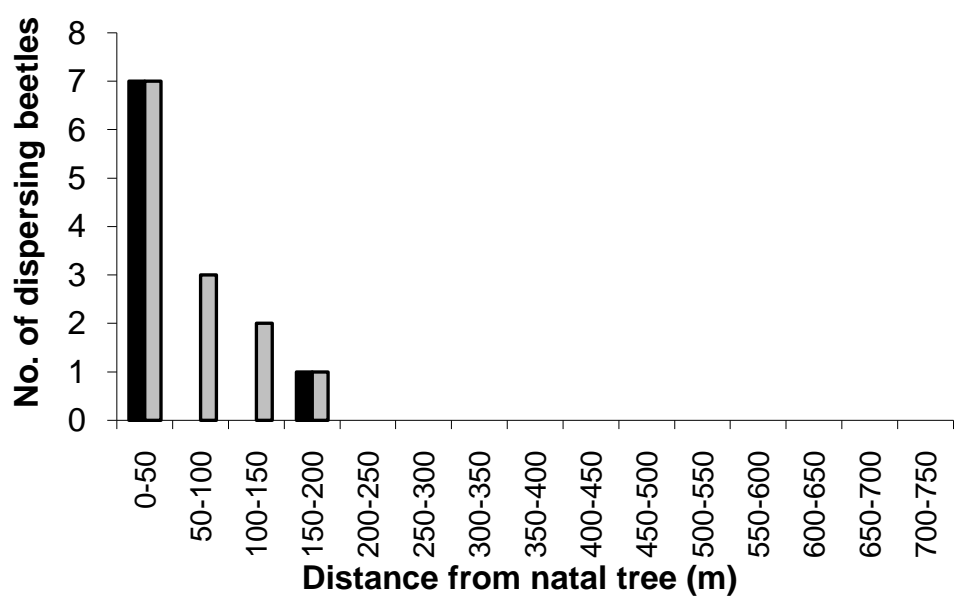

b)

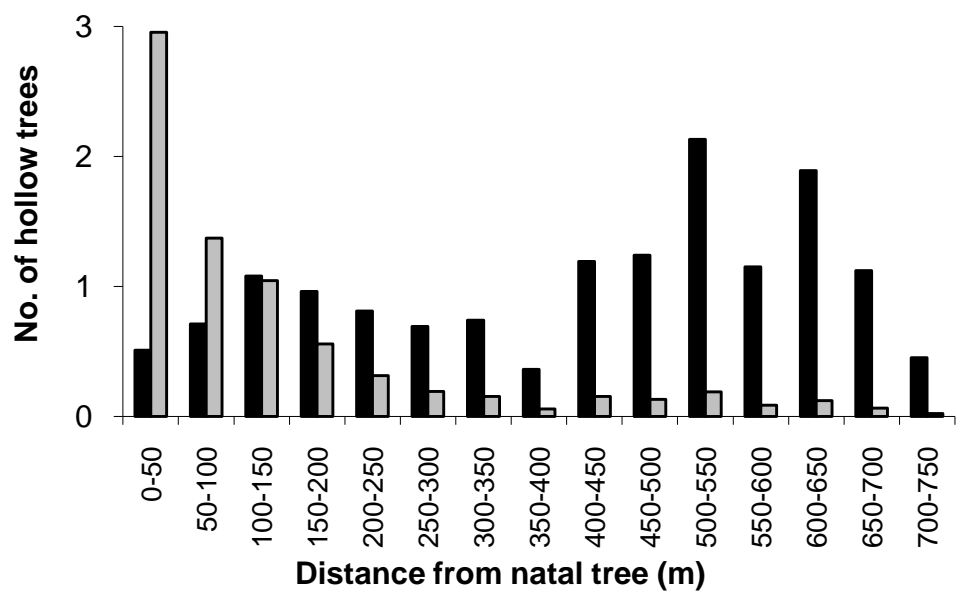

